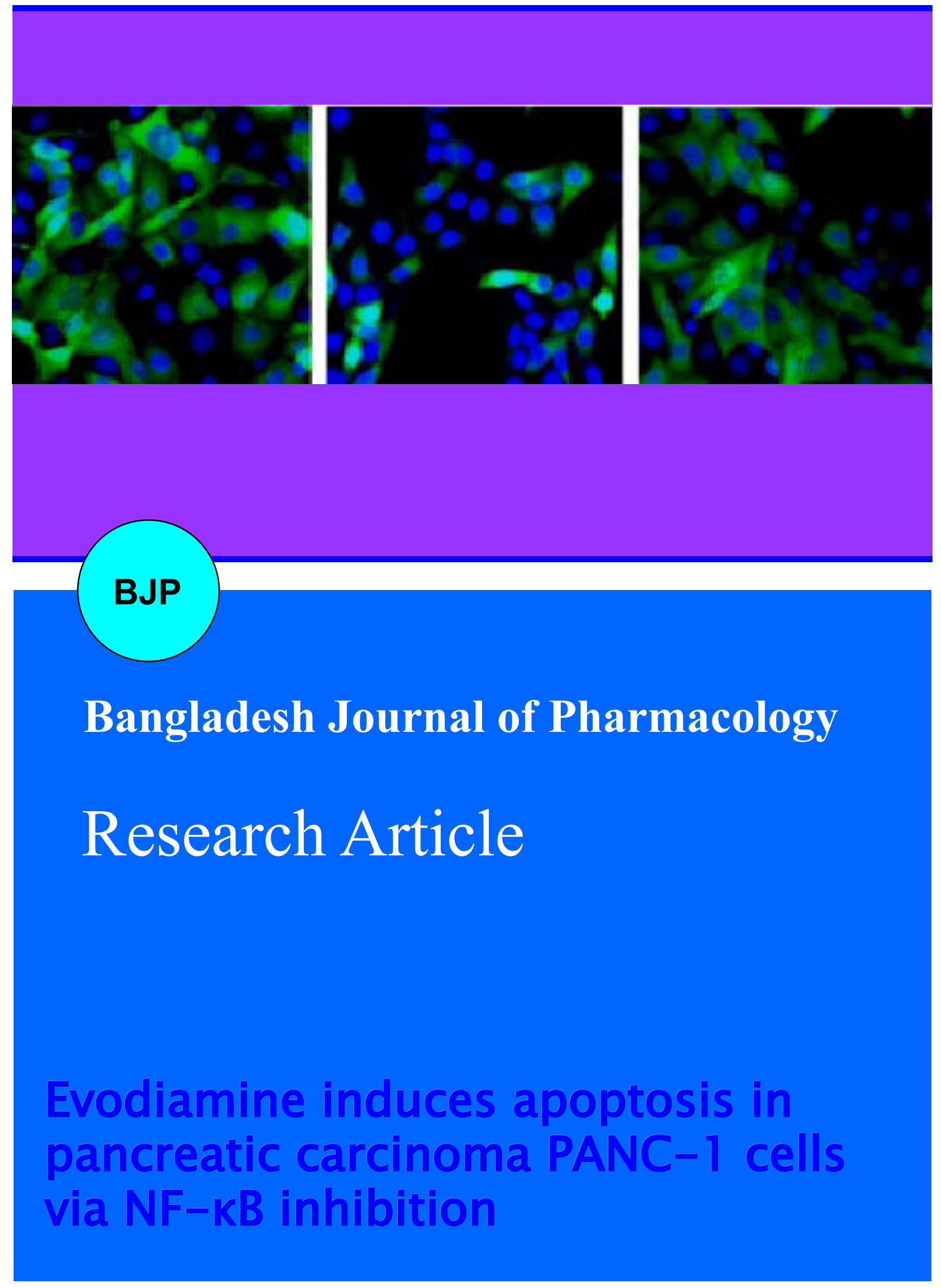




\title{
Evodiamine induces apoptosis in pancreatic carcinoma PANC-1 cells via NF-KB inhibition
}

\author{
Muhammad Khan',2, Javed Iqbal Qazi ${ }^{2}$, Azhar Rasul, Yongchen Zheng' and Tonghui Ma1 \\ ${ }^{1}$ Central Research Laboratory, Jilin University Bethune Second Hospital, Changchun 130 041, P. R. China; \\ ${ }^{2}$ Department of Zoology, University of the Punjab, Quaid-e-Azam Campus, Lahore 54 590, Pakistan.
}

\begin{tabular}{|l|}
\hline Article Info \\
\hline Received: $\quad$ 30 November 2012 \\
Accepted: $\quad$ 6 December 2012 \\
Available Online: $\quad$ 24 December 2012 \\
DOI: 10.3329/bjp.v8i1.12802 \\
\\
\\
Cite this article: \\
Khan M, Qazi JI, Rasul A, Zheng Y, \\
Ma T. Evodiamine induces apoptosis \\
in pancreatic carcinoma PANC-1 cells \\
via NF-kB inhibition. Bangladesh J \\
Pharmacol. 2013; 8: 8-14.
\end{tabular}

\begin{abstract}
NF-kB constitutively expresses in human pancreatic cancer cells and has been implicated in pancreatic tumorigenesis. Evodiamine, a bioactive alkaloid has been shown to possess anti-oxidant, anti-inflammatory and antitumor properties. In the present study, the anti-pancreatic cancer potential of evodiamine have been evaluated. Evodiamine effectively inhibited growth and induced apoptosis in PANC-1 cells in a dose-dependent manner. SN50 (NF-kBp65 inhibitor) significantly increased the evodiamine-induced apoptotic cell death in PANC-1 cells, indicating that NF-kB is involved in evodiamine-induced apoptotic cell death. Furthermore, Western blot analysis showed that evodiamine inhibited the constitutive activation of NF-kB p65, decreased the expression of anti-apoptotic protein $\mathrm{Bcl}-2$, increased the expression of pro-apoptotic protein Bax and cleaved caspase-3 in PANC-1 cells in a dose-dependent manner. The present study suggests that evodiamine induces apoptosis in PANC-1 cells via NF-kBp65 inhibition and apoptosis regulators modulation.
\end{abstract}

\section{Introduction}

Pancreatic carcinoma is the fourth leading cause of cancer related deaths in United States. Despite continuing advances in radiotherapy, surgery and chemotherapy, the overall 5-year survival rate remains less than 3 years (Khan et al., 2012a). Currently, gemcitabine is the most effective chemotherapeutic drug for the treatment of pancreatic cancer. However, even with this drug the objective tumor response rate remains considerably low (Khan et al., 2012a; Ou et al., 2010). Furthermore, gemcitabine is reported to up-regulate nuclear factor- $\mathrm{KB}$ (NF$\mathrm{\kappa B})$ in pancreatic cancer cells which is associated with the development of drug resistance (Ou et al., 2010). The transcription factor nuclear factor- $\mathrm{KB}(\mathrm{NF}-\mathrm{\kappa B})$ is constitutively activated in human pancreatic cancer tissues and pancreatic cancer cell lines. NF-KB is involved in the regulation of the transcription of a serial of proliferation and anti-apoptotic genes such as cyclin
D1, Bcl-2 and XIAP (Ou et al., 2010; Yip-Schneider et al., 2005). Constitutive activation of NF-KB is implicated in pancreatic tumorigenesis and resistance to many chemotherapeutic agents such as TNFa (Bharadwaj et al., 2011) and gemcitabine (Chen et al., 2012; Ou et al., 2010). In the light of above findings, it is important to evaluate the chemotherapeutic potential of $\mathrm{NF}-\mathrm{kB}$ inhibitors.

In the present study, we performed high throughput screening of compound library derived from Chinese herbs, using PANC-1 cell line. The compounds exhibiting promising anti-pancreatic cancer activity were selected for high content screening to observe their effects on NF-kB inducible activation. The high content screening of anti-pancreatic cancer compounds were performed using recombinant U2OS cell line, stably expressing human NF-kB fused to the N-terminal of enhanced green fluorescence protein (EGFP). This 
screening method allowed us to identify the antipancreatic cancer compounds inhibiting translocation of NF-kB p65 from cytoplasm to nucleus. During this screening method, evodiamine was found to be a potent inhibitor of NF-kB p65. Evodiamine is one of the main components of Evodiae fructus (Takada et al., 2005). It has been shown to exhibit anti-cancer activities against various cancer cell lines including human malignant melanoma, breast cancer (Zhang et al., 2004), cervical cancer (Yang et al., 2008), colorectal cancer (Yang et al., 2009), lung cancer (Takada et al., 2005), prostate cancer (Kan et al., 2004) and leukemia (Lee et al., 2011) through different mechanisms. However, the anti-cancer effect and molecular mechanism of evodiamine on pancreatic cancer remain largely unknown.

In the present study, we examined the anti-pancreatic cancer potential of evodiamine using PANC-1 cell line. The data showed that evodiamine induced apoptosis in PANC-1 cells by inhibiting spontaneous NF-кBp65 activation and the expression of $\mathrm{NF}-\mathrm{KB}$ regulated protein Bcl-2.

\section{Materials and Methods \\ Reagents and antibodies}

All the chemicals were purchased from Sigma unless otherwise stated. Evodiamine was purchased from Tauto Biotech. Co., Ltd. (Shanghai, China) and purity (> 99\%) was determined by HPLC. The chemical structure of evodiamine is shown in Figure 1A. Antibodies specific to NF-kBp65, Bcl-2, Bax, Caspase-3 and $\beta$-actin were purchased from Beyotime Institute of Technology (Shanghai, China), whereas Horseradish peroxidaseconjugated secondary antibodies (goatanti-rabbit, goatantimouse) were purchased from Sigma (Beijing, China).

\section{Cell culture and treatments}

Human pancreatic carcinoma cells PANC-1 were obtained from Shanghai Cell Bank whereas recombinant U2OS cells were obtained from Thermo Scientific (Beijing China). Cells were cultured in Dulbecco's Modified Eagle's Medium (DMEM) supplemented with $10 \%$ fatal bovine serum (FBS), 100 units $/ \mathrm{mL}$ penicillin and $100 \mu \mathrm{g} / \mathrm{mL}$ streptomycin at $37^{\circ} \mathrm{C}$ with $5 \% \mathrm{CO}_{2}$ in humidified atmosphere. Cells were treated with various concentrations of evodiamine dissolved in DMSO with a final DMSO concentration of $1 \%$ for 24 hours. DMSO treated cells were used as control.

\section{Determination of cell viability}

Cell viability was determined by MTT assay as described by us previously (Khan et al., 2012a). Briefly PANC1 cells were seeded into 96-well culture plates in triplicates and treated with DMSO or various concen- trations of evodiamine $(0.1-10 \mu \mathrm{M})$ for 24 hours. Following treatment, the MTT reagent was added (500 $\mu \mathrm{g} / \mathrm{mL}$ ) and cells were further incubated at $37^{\circ} \mathrm{C}$ for 4 hours. Subsequently, $150 \mu \mathrm{L}$ DMSO was added to dissolve farmazan crystals and absorbance was measured at $570 \mathrm{~nm}$ in a microplate reader (Thermo Scientific). The percentage of cell viability was calculated as follows:

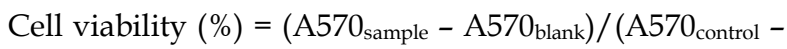
A570 blank) $\times 100$

The $\mathrm{IC}_{50}$ Values were calculated using GraphPad Prism 5 .

\section{NF-кBp65 translocation assay}

The recombinant U2OS cells, stably expressing human $\mathrm{NF}-\mathrm{kB}$ fused to the N-terminal of enhanced green fluorescence protein (EGFP) were used to examine the translocation of NF- $\mathrm{KB}$ into nucleus using NF-kB redistribution HCS assay kit (Thermo Scientific, USA). Briefly, 6000 cells were plated into 96-well plate and incubated at $37^{\circ} \mathrm{C}$ over night. After incubation, medium was replaced with cell wash buffer and cells were further incubated at $37^{\circ} \mathrm{C}$ for 24 hours with $5 \% \mathrm{CO} 2$ in a humidified atmosphere. The cells were then incubated with $10 \mathrm{ng} / \mathrm{mL}$ of TNFa or a combination of $10 \mathrm{ng} / \mathrm{mL}$ TNFa and $1 \mu \mathrm{M}$ evodiamine for $30 \mathrm{~min}$. Fixation, permeabilization and immunofluorescence staining of cells were performed according to the manufacturer's instructions.

\section{Live/dead assay}

Live and dead cells were quantified using fluorescent probes calcein acetoxymethylester (calcein AM) and propidium iodide (PI) as described by us previously (Khan et al., 2012b; Ding et al., 2012). Briefly PANC-1 cells were treated with 0.5 and $1 \mu \mathrm{M}$ evodiamine in the presence or absence of NF-kBp65 inhibitor, SN50 (Enzo Life Science) for 24 hours. Subsequently, treated and untreated cells were collected, washed with phosphate buffered saline (PBS) and incubated with PBS solution containing $2 \mu \mathrm{M}$ calcein AM and $4 \mu \mathrm{M}$ PI in the dark for $20 \mathrm{~min}$ at room temperature. After washing, cells were resuspended in PBS and analyzed for the fluorescence of calcein and PI by fluorescence microscope (Olympus $1 \times 71$ ). At the end, 100 cells were counted microscopically for the percentage of live and dead cells.

\section{Apoptosis assay}

PANC-1 cells were treated with 0.5 and $1 \mu \mathrm{M}$ evodiamine in the presence or absence of NF-kBp65 inhibitor, SN50 $(20 \mu \mathrm{M})$ for 24 hours. Following incubation, floating and adherent cells were collected by centrifugation, washed with PBS and resuspended in $500 \mu \mathrm{L}$ of binding buffer containg $5 \mu \mathrm{L}$ annexin $\mathrm{V}$ and $5 \mu \mathrm{L}$ propidium iodide and incubated in the dark for $15 \mathrm{~min}$ according to the manufacturer's instructions (KeyGen, 
Shanghai, China). At the end, samples were analyzed by flow cytometry (Beckman Coulter, Epics XL) for the percentage of apoptotic cells.

\section{Immunobloting}

Proteins were isolated from control and evodiamine treated cells as described by us previously (khan et al., 2012a). Nuclear proteins were extracted using cytosolic and nuclear extraction kit (KeyGen, China) according to the manufacturer's instructions. The protein concentrations were determined using NanoDrop 1000 (Thermo Scientific, USA). $50 \mu \mathrm{g}$ proteins were electrophoresed on $10 \%$ sodium dodecyl sulfate polyacrylamide gel electrophoresis (SDS-PAGE) and transferred to Polyvinylidene fluoride (PVDF) membrane. After blocking with $5 \%(\mathrm{w} / \mathrm{v})$ nonfat milk and washing with Trisbuffered saline-Tween solution (TBST), membranes were incubated overnight at $4^{\circ} \mathrm{C}$ with NF-kBp65 (1:500, dilution), Bcl-2 (1:1000, dilution), Bax (1:300, dilution), Caspase-3 (1:500, dilution) and $\beta$-actin (1:400, dilution) antibodies respectively. After washing, the blots were incubated with horseradish peroxidase-conjugated goat anti-rabbit IgG or goat anti-mouse IgG secondary antibodies (1:5000) for 1 hour at room temperature. After washing with TBST, signals were detected using ECL plus chemiluminescence's kit on X-ray film

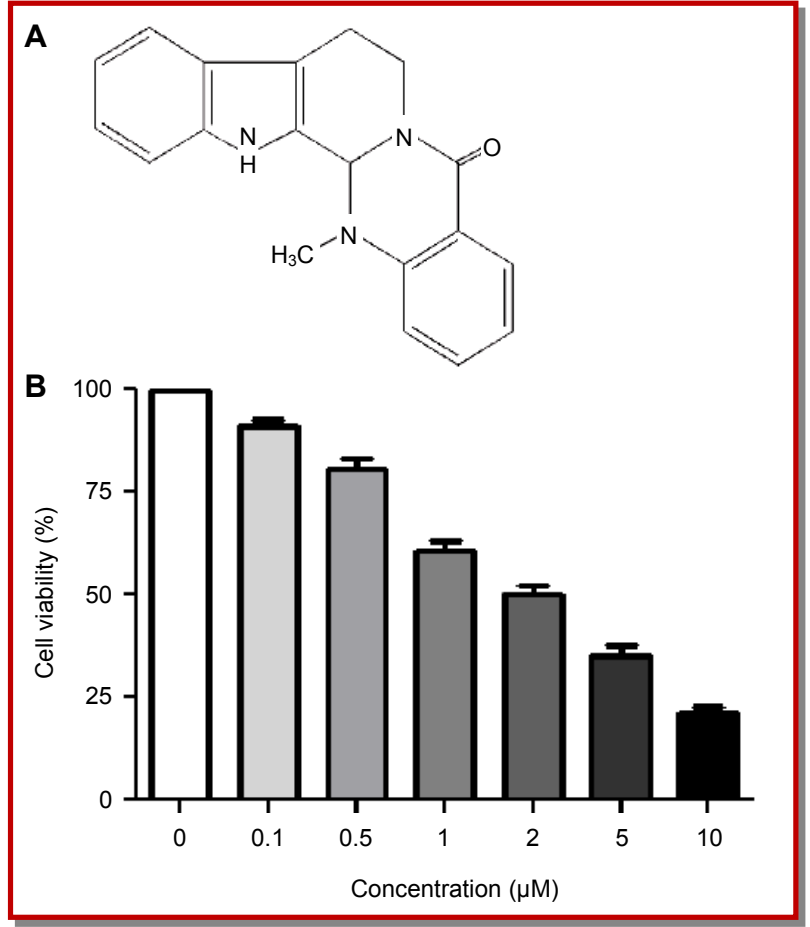

Figure 1: (A) Chemical structure of evodiamine; (B) Effect of evodiamine on PANC-1 cells viability. PANC-1 cells were treated with indicated concentrations of evodiamine for 24 hours and cell viability was determined by MTT assay. Data are expressed as Mean \pm SEM of three independent experiments. Columns not sharing the same superscript letter differ significantly $(\mathrm{p}<0.05)$

\section{(Millipore Corporation).}

\section{Statistical analysis}

The results are expressed as mean \pm SEM. from three different experiments and statistically compared with control group or within the groups using one-way ANOVA followed by Tukey's Multiple Comparison Test.

\section{Results}

The cytotoxic effect of evodiamine on pancreatic carcinoma was evaluated using PANC-1 cell line. Evodiamine increased the growth inhibition of PANC-1 cells in a dose-dependent manner (Figure 1B). The concentration to achieve $50 \%$ growth inhibition $\left(\mathrm{IC}_{50}\right)$ was 2 $\mu \mathrm{M}$. Less toxic concentrations of evodiamine ( 0.5 and 1 $\mu \mathrm{M})$ were selected for further study.

NF-kBp65 is constitutively activated in pancreatic carcinoma cells. To observe whether evodiamine can inhibit NF-kBp65 activation, we tested evodiamine for its inhibitory effect against NF-kBp65 translocation activated by TNFa, using a model cell line U2OS, by HCS assay. As shown in Figure 2, evodiamine inhibited TNFa-induced translocation of NF-kBp65 from cytoplasm into the nucleus.

To characterize in detail whether evodiamine induced cell death or merely inhibited the cells growth, we treated PANC- 1 cells with 0.5 and $1 \mu \mathrm{M}$ evodiamine for 24 hours. After incubation with evodiamine for 24 hours, cells were harvested and stained with calcein $\mathrm{AM}$ and PI to quantify live and dead cells. Figure 3A shows the staining of cells with calcein AM and PI. Live cells took up calcein AM, deesterified and retained the green calcein dye while dead cells were unable to retain calcein or to exclude PI. Live (green) and dead cells (red) were counted microscopically. The data showed that evodiamine induced cell death in PANC-1 cells in a dose-dependent manner. Evodiamine has inhibited the TNFa-induced activation of NF-kBp65 in U2OS cells. Next, we wondered if inhibition of NF-kBp65 activation is involved in evodiamine-induced cell death in PANC1 cells. We treated PANC-1 cells with $1 \mu \mathrm{M}$ evodiamine in the presence of $20 \mu \mathrm{M}$ SN50, a specific NF-kBp65 inhibitor and cell death was measured by live/dead assay. As shown in Figure 3, treatment of cells with SN50 potentiated the evodiamine-induced cell death in PANC-1 cells. The data demonstrated that evodiamine induced cell death in PANC-1 cells via NF-кBp65 inhibition.

To study the nature of cell death induced by evodiamine in PANC-1 cells, we treated the cells with 0.5 and $1 \mu \mathrm{M}$ evodiamine or with a combination of 1 $\mu \mathrm{M}$ evodiamine and $20 \mu \mathrm{M}$ SN50 for 24 hours and cells 


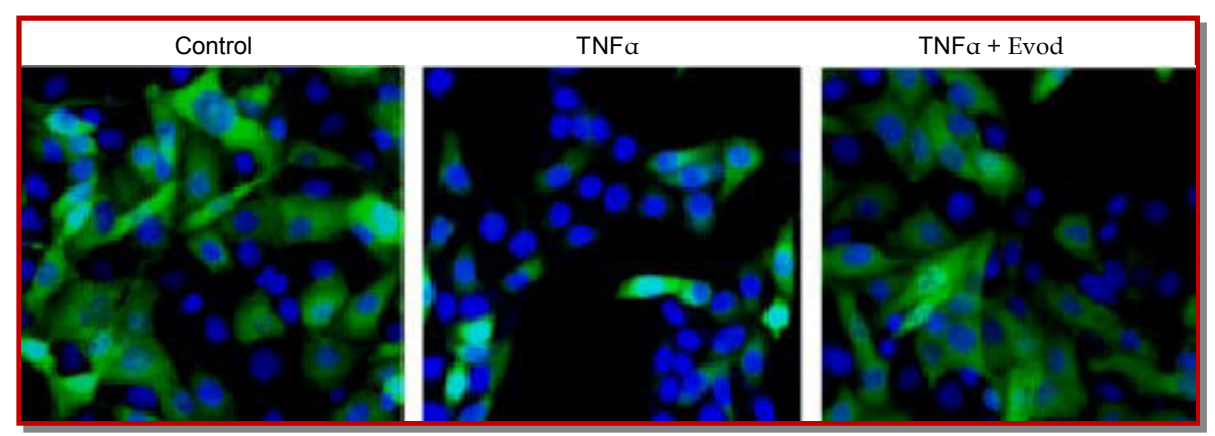

Figure 2: Effect of evodiamine on redistribution of NF-kBp65. U2OS cells were incubated with $10 \mathrm{ng}$ TNFa or a combination of 10 ng TNFa and $1 \mu \mathrm{M}$ evodiamine for $30 \mathrm{~min}$ and NF-kBp65 translocation in the nucleus was observed using NF-kB redistribution HCS assay kit

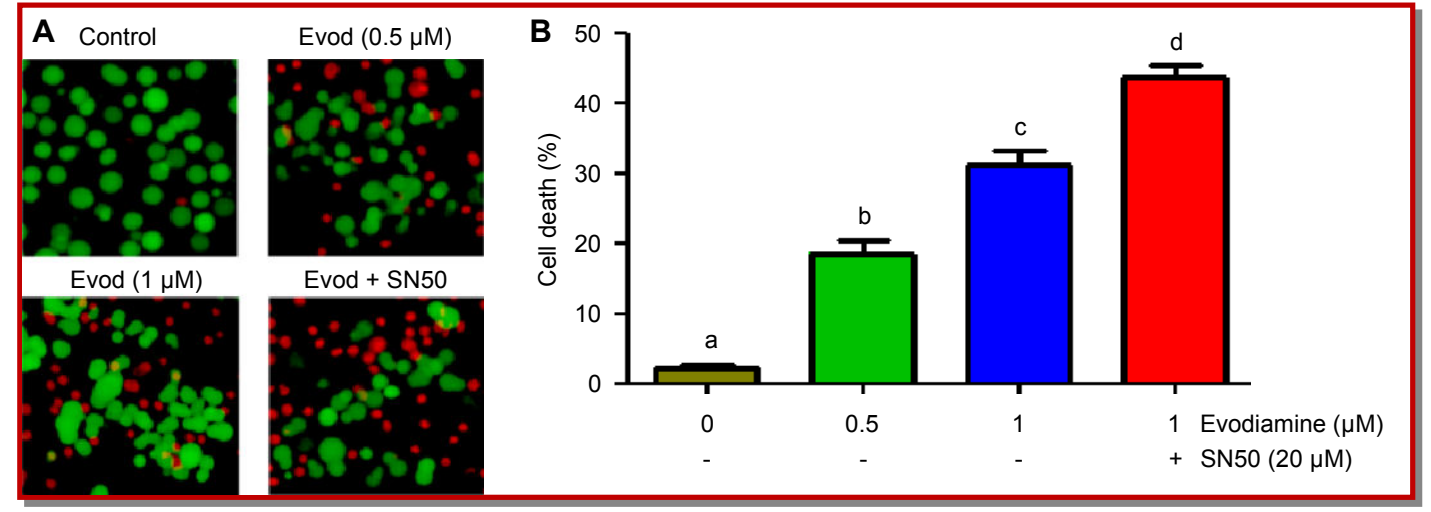

Figure 3: Effect of evodiamine on cell death of PANC-1 cells. (A) PANC-1 cells were treated with indicated concentrations of evodiamine in the presence or absence of $20 \mu \mathrm{M}$ SN50 for 24 hours and cell death was examined using Live/Dead assay; (B) Data are expressed as Mean \pm SEM of three independent experiments. Columns not sharing the same superscript letter differ significantly $(\mathrm{p}<0.05)$

undergoing apoptosis/necrosis were determined by flow cytometry analysis after staining with annexin VFITC and PI. The data demonstrated that evodiamine induced apoptotic cell death in PANC-1 cells in a dosedependent manner. Furthermore, SN50 potentiated the evodiamine-induced apoptosis, indicating that evodiamine induced apoptosis in PANC-1 cells by inhibiting spontaneous NF-kB activation (Figure 4).

Constitutive activation of NF-kB in pancreatic carcinoma has been associated with drug resistance. Since, SN50 increased the apoptotic effect of evodiamine in PANC-1 cells; we measured the expression of NFкBp65 in nuclear extract. As shown in Figure 5A, evodiamine inhibited the spontaneous expression of NF $-\mathrm{kBp} 65$ in evodiamine-treated PANC-1 cells in a dosedependent manner. Since anti-apoptotic protein Bcl-2 is one of the crucial down-stream mediators of NF-kB, we measured the expression of Bcl-2. The data showed that evodiamine significantly decreased the expression of $\mathrm{Bcl}-2$ and increased the expression of pro-apoptotic protein Bax in PANC-1 cells in a dose-dependent manner (Figure 5A). Cleavage of caspase-3 is a hallmark of apoptotic cell death. Next, we observed the expression of caspase- 3 in evodiamine-treated PANC-1 cells by Western blot analysis. Figure $5 \mathrm{~B}$ clearly indi- cates the cleavage of caspase- 3 in evodiamine-treated cells.

\section{Discussion}

Human pancreatic cancer has a very poor prognosis; even after curative resection, and is currently fourth leading cause of cancer-related deaths in United States (Fujioka et al., 2003; Khan et al., 2012a). It is well established that NF-KB constitutively expressed in pancreatic cancer cells. The constitutive activation of NF- $\mathrm{kB}$ is believed to promote inhibition of apoptosis and resistance to chemotherapy (Arlt and Schafer, 2002; Holocomb et al., 2008; Liptay et al., 2003). This notion is further supported by the fact that inactivation of NF-KB sensitizes cancer cells to conventional chemotherapies (Banerjee et al., 2005; Banerjee et al., 2007). Therefore, treating pancreatic cancer with NF-kB inhibitors can improve the outcomes of chemotherapy. The present study was conducted to identify NF-kBp65 inhibitors from a natural compound library derived from traditional Chinese herbs. Evodiamine was found to be a potent inhibitor of NF-kBp65 during our screening process and was selected to explore its effects on pancreatic carcinoma PANC-1 cells. Evodiamine 


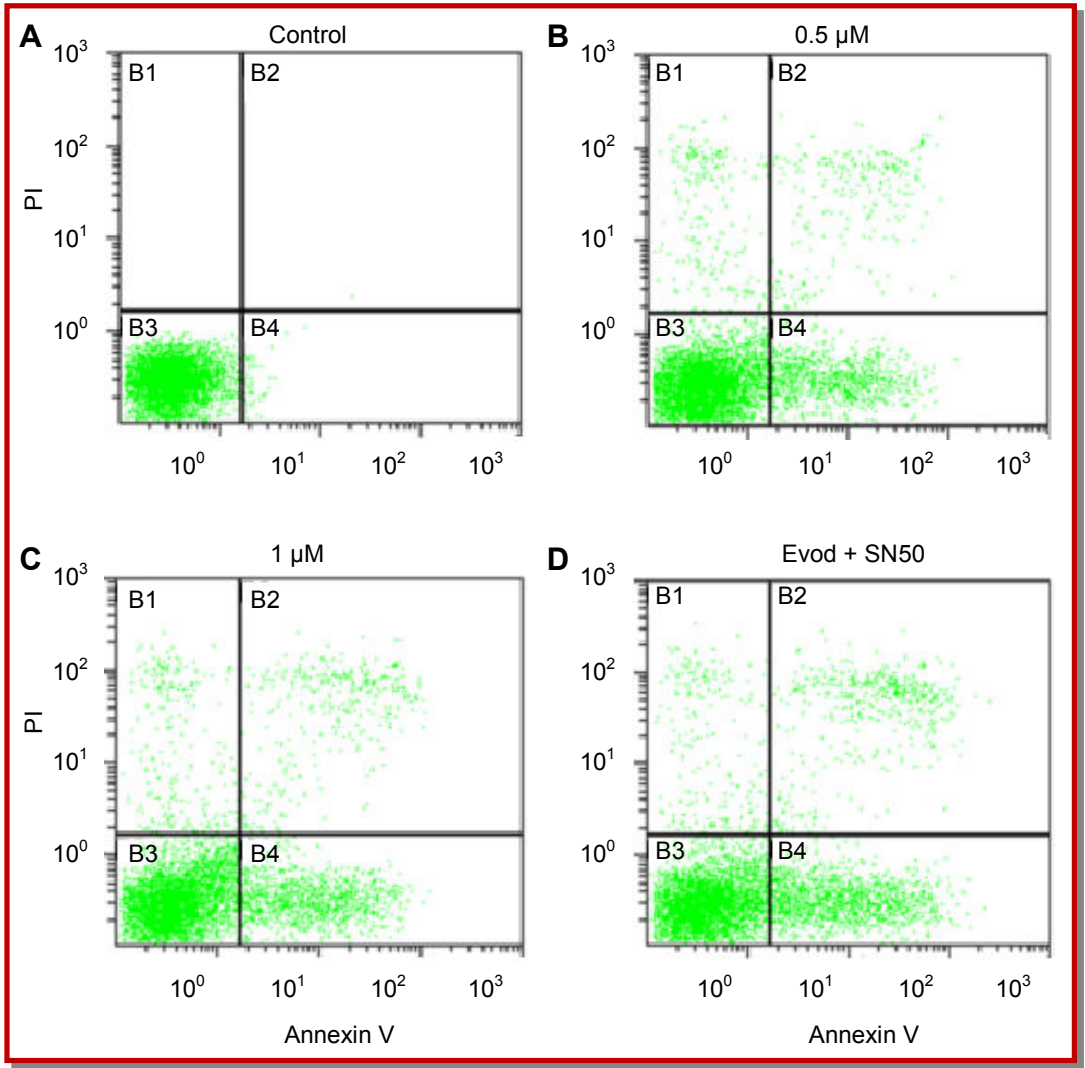

Figure 4: Flow cytometry analysis of cell apoptosis. (A) PANC-1 cells were treated with indicated concentrations of evodiamine in the presence or absence of $20 \mu \mathrm{M}$ SN50 for 24 hours and apoptosis was determined by flow cytometry after Annexin V/PI staining; (B) Data are expressed as Mean \pm SEM of three independent experiments. Columns not sharing the same superscript letter differ significantly $(\mathrm{p}<0.05)$

effectively inhibited the growth of PANC-1 cells in a dose-dependent manner. To further clarify that whether evodiamine induces cell death or merely inhibits growth of PANC-1 cells, we performed live/dead assay and apoptosis assay. The data from live/dead assay demonstrated that evodiamine induced cell death in pancreatic cancer cells. To further identify the nature of cell death, we performed apoptosis assay. We found that evodiamine induced apoptotic cell death in PANC1 cells dose-dependently. The results are in line with previous reports that evodiamine inhibits growth and induces apoptosis in various cancer cell lines of different origin (Kan et al., 2004; Lee et al., 2011; Takada et al., 2005; Yang et al., 2009; Zhang et al., 2004).

Previous reports have demonstrated that inhibition of spontaneous NF-KB activation can potentiate the anticancer effect of various chemotherapeutic agents (Banerjee et al., 2007). Thus, we treated the cell with evodiamine in the presence of SN50, a specific NFкBp65 inhibitor and cell death was measured by live/ dead assay and apoptosis assay. We found that treatment of cells with SN50 augmented evodiamineinduced cell death in PANC-1 cells. The data clearly indicates that evodiamine induces apoptosis in PANC-1 cells through NF-kB inhibition. To further confirm the inhibition of constitutive activation of NF-kBp65 by evodiamine, we examined the expression of NF-kBp65 in nuclear extract by Western blot analysis. The results showed that evodiamine significantly inhibited the expression of NF-KBp65 in nuclear extract in a dosedependent manner. The results are further supported by a previous study by Takada et al. (2005) who found a similar inhibitory effect of evodiamine on constitutive and inducible NF-KB activation in lung adenocarcinoma, T-cell lymphoma and multiple myeloma.

The role of Bcl-2 family proteins is well established in mitochondrial mediated apoptosis. The expression of anti-apoptotic protein Bcl-2 is positively regulated by NF-kB. The overexpression of anti-apoptotic protein Bcl -2 impairs the mitochondrial apoptosis by neutralizing pro-apoptotic protein Bax and has been associated with tumor survival and chemoresistance in pancreatic cancer cells (Liu et al., 2010; Ou et al., 2010). Since evodiamine inhibited the activation of NF-KBp65 in pancreatic cancer cells; and Bcl-2 is one of the crucial downstream target genes of NF-kB, we were interested to observe the expressions of Bcl-2 and Bax. We found that the expression of Bcl-2 decreased while the expression of Bax increased in cells exposed to evodiamine in a dose-dependent manner. The results are in line with 


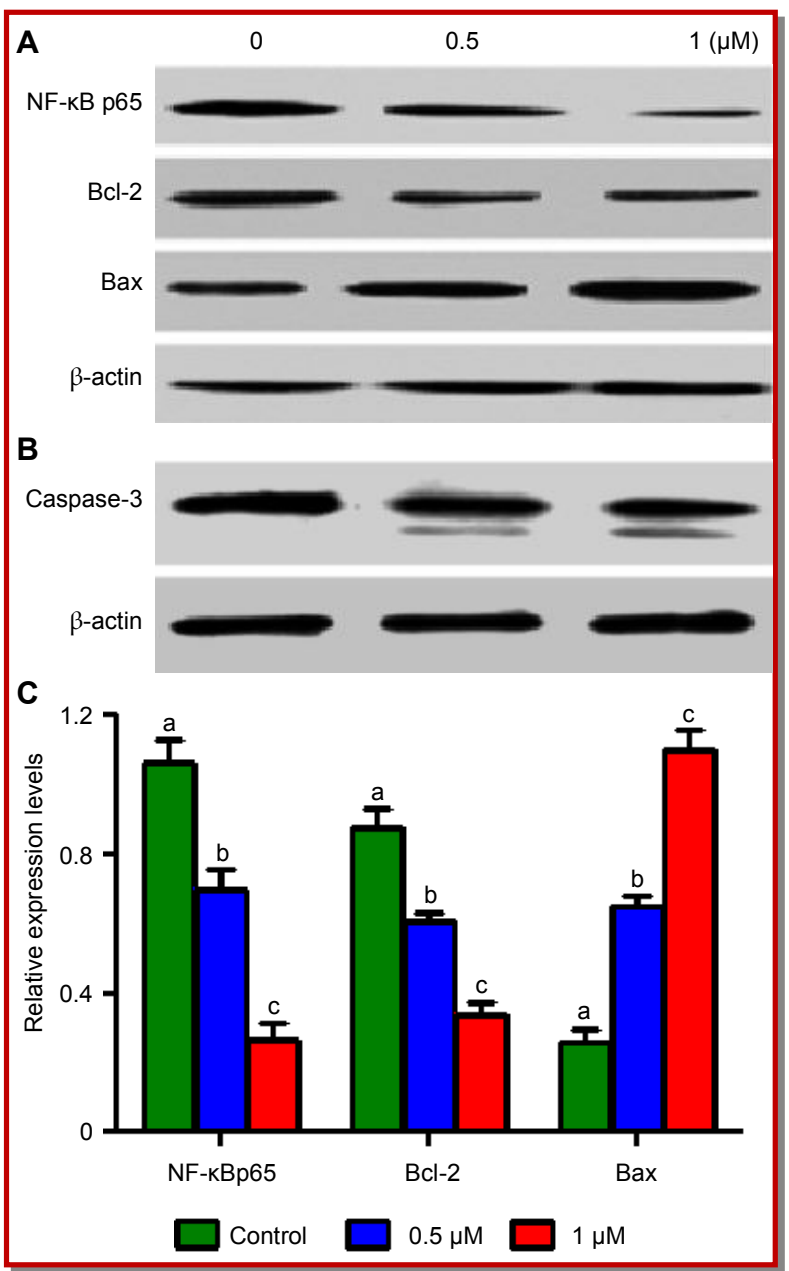

Figure 5: Effect of evodiamine on apoptosis regulators in PANC -1 cells. PANC-1 cells were treated with indicated concentrations of evodiamine for 24 hours. Total cell lysates and nuclear proteins were extracted as described in Materials and Methods section. $50 \mu \mathrm{g}$ proteins were subjected to Western blot for the expressions of (A) NF-kB p65, Bcl-2 and Bax; (B) caspase-3; (C) Data from Figure A are expressed as Mean \pm SEM of three independent experiments. Columns not sharing the same superscript letter within the group differ significantly $(p<0.05)$

previous reports that evodiamine induced apoptosis in other cell lines by modulating $\mathrm{Bcl}-2$ family proteins (Yang et al., 2009).

Caspases are recognized as key mediators of apoptosis. Among the identified caspases, caspase- 3 is the best characterized effector caspase, which is in the downstream of Bcl-2 and Bax. Cleavage of caspase- 3 is a hallmark in the process of apoptosis. Once activated, caspase-3 leads to the final stage of cellular death by proteolytic cleavage of poly (ADP ribose) polymerase (PARP) and DNA on the one hand and activation of pro -apoptotic factors on the other hand (Gong et al., 2004; Kim et al., 2007; Yang et al., 2009). Therefore, we examined the changes in the expression of caspase- 3 in
PANC-1 cells after exposure to evodiamine, by Western blot analysis. We found that evodiamine treatment stimulated the cleavage of caspase- 3 in a dosedependent manner.

In conclusion, the data demonstrated that evodiamine inhibited the growth of PANC-1 cells by inducing apoptosis via inhibition of NF-kB activation which led to decrease Bcl-2/Bax ratio and ultimately cleavage of caspase-3. Therefore, our study supports the possible use of evodiamine as a therapeutic agent for pancreatic carcinoma, not only to produce apoptotic effects but also to overcome tumor resistance to chemotherapy.

\section{Acknowledgement}

This work is supported by Ministry of Education of Pakistan and Chinese Scholarship Council of China.

\section{References}

Arlt A, Schafer H. NF kappaB-dependent chemoresistance in solid tumors. Int J Clin Pharmacol Ther. 2002; 40: 336-47.

Banerjee S, Zhang Y, Ali S, Bhuiyan M, Wang Z, Chiao PJ, Philip PA, Abbruzzese J, Sarkar FH. Molecular evidence for increased antitumor activity of gemcitabine by genistein in vitro and in vivo using an orthotopic model of pancreatic cancer. Cancer Res. 2005; 65: 9064-72.

Banerjee S, Zhang Y, Wang Z, Che M, Chiao PJ, Abbruzzese JL, Sarkar FH. In vitro and in vivo molecular evidence of genistein action in augmenting the efficacy of cisplatin in pancreatic cancer. Int J Cancer. 2007; 120: 906-17.

Bharadwaj U, Marin-Muller C, Li M, Chen C, Yao Q. Mesothelin confers pancreatic cancer cell resistance to TNFalpha-induced apoptosis through Akt/PI3K/NF-kappaB activation and IL-6/Mcl-1 overexpression. Mol Cancer. 2011; 10: 106.

Chen D, Niu M, Jiao X, Zhang K, Liang J, Zhang D. Inhibition of AKT2 enhances sensitivity to gemcitabine via regulating PUMA and NF-kappaB signaling pathway in human pancreatic ductal adenocarcinoma. Int J Mol Sci. 2012; 13: 1186-1208.

Fujioka S, Sclabas GM, Schmidt C, Niu J, Frederick WA, Dong QG, Abbruzzese JL, Evans DB, Baker C, Chiao PJ. Inhibition of constitutive NF-kappa B activity by I kappa B alpha M suppresses tumorigenesis. Oncogene 2003; 22: 1365-70.

Gong X, Wang M, Wu Z, Tashiro S, Onodera S, Ikejima T. Pseudolaric acid B induces apoptosis via activation of c-Jun $\mathrm{N}$-terminal kinase and caspase-3 in HeLa cells. Exp Mol Med. 2004; 36: 551-56.

Holcomb B, Yip-Schneider M, Schmidt CM. The role of nuclear factor kappaB in pancreatic cancer and the clinical applications of targeted therapy. Pancreas 2008; 36: 225-35.

Kan SF, Huang WJ, Lin LC, Wang PS. Inhibitory effects of evodiamine on the growth of human prostate cancer cell 
line LNCaP. Int J Cancer. 2004; 110: 641-51.

Khan M, Ding C, Rasul A, Yi F, Li T, Gao H, Gao R, Zhong L, Zhang $\mathrm{K}$, Fang $\mathrm{X}, \mathrm{Ma} \mathrm{T}$. Isoalantolactone induces reactive oxygen species mediated apoptosis in pancreatic carcinoma PANC-1 cells. Int J Biol Sci. 2012a; 8: 533-47.

Khan M, Yu B, Rasul A, Al Shawi A, Yi F, Yang H, Ma T. Jaceosidin Induces Apoptosis in U87 glioblastoma cells through G2/M Phase Arrest. Evid Based Complement Alternat Med. 2012b; 2012: 703034

Kim MJ, Kim DH, Lee KW, Yoon DY, Surh YJ. Jaceosidin induces apoptosis in ras-transformed human breast epithelial cells through generation of reactive oxygen species. Ann N Y Acad Sci. 2007; 1095: 483-95.

Lee TJ, Kim EJ, Kim S, Jung EM, Park JW, Jeong SH, Park SE, Yoo YH, Kwon TK. Caspase-dependent and caspaseindependent apoptosis induced by evodiamine in human leukemic U937 cells. Mol Cancer Ther. 2006; 5: 2398-407.

Liptay S, Weber CK, Ludwig L, Wagner M, Adler G, Schmid RM. Mitogenic and antiapoptotic role of constitutive NFkappaB/Rel activity in pancreatic cancer. Int J Cancer. 2003; 105: 735-46

Liu JW, Cai MX, Xin Y, Wu QS, Ma J, Yang P, Xie HY, Huang DS. Parthenolide induces proliferation inhibition and apoptosis of pancreatic cancer cells in vitro. J Exp Clin Cancer Res. 2010; 29: 108.

Ou YQ, Zhu W, Li Y, Qiu PX, Huang YJ, Xie J, He SM, Zheng
XK, Leng TD, Xu D, Yan GM. Aspirin inhibits proliferation of gemcitabine-resistant human pancreatic cancer cells and augments gemcitabine-induced cytotoxicity. Acta Pharmacol Sin. 2010; 31: 73-80.

Takada Y, Kobayashi Y, Aggarwal BB. Evodiamine abolishes constitutive and inducible NF-kappaB activation by inhibiting IkappaBalpha kinase activation, thereby suppressing NF-kappaB-regulated antiapoptotic and metastatic gene expression, up-regulating apoptosis, and inhibiting invasion. J Biol Chem. 2005; 280: 17203-12.

Yang J, Wu LJ, Tashino S, Onodera S, Ikejima T. Reactive oxygen species and nitric oxide regulate mitochondriadependent apoptosis and autophagy in evodiamine-treated human cervix carcinoma HeLa cells. Free Radic Res. 2008; 42: $492-504$.

Yang ZG, Chen AQ, Liu B. Antiproliferation and apoptosis induced by evodiamine in human colorectal carcinoma cells (COLO-205). Chem Biodivers. 2009; 6: 924-33.

Yip-Schneider MT, Nakshatri H, Sweeney CJ, Marshall MS, Wiebke EA, Schmidt CM. Parthenolide and sulindac cooperate to mediate growth suppression and inhibit the nuclear factor-kappa B pathway in pancreatic carcinoma cells. Mol Cancer Ther. 2005; 4: 587-94.

Zhang Y, Zhang QH, Wu LJ, Tashiro S, Onodera S, Ikejima T. Atypical apoptosis in L929 cells induced by evodiamine isolated from Evodia rutaecarpa. J Asian Nat Prod Res. 2004; 6: 19-27.

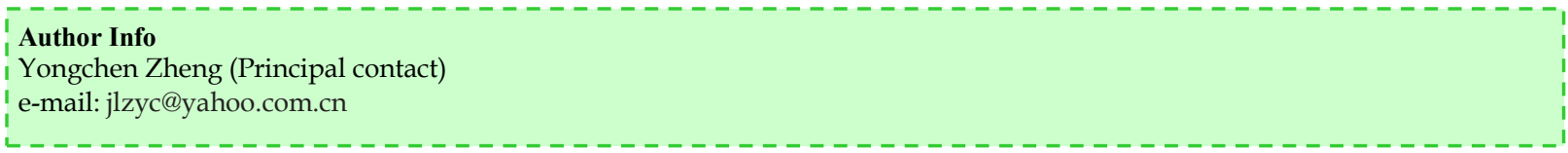

